of splint or swing, motion will occur at the place of least resistance, which is the hip joint." I have found that to be the case. I have found it a convenient way to treat a compound fracture of the femur when there is an abscess discharging pus. You can release one of the bands coming under the limb and dress the wound without disturbing the fracture.

Dr. P. B. Magnuson, Chicago: I think Dr. Kidner has expressed the views of most of us when he said that he had tried all methods and none of them worked all the time. I think most of us who have done fracture work fully appreciate that. We condemn the Lane plate and the ivory plate and the bone plate; but when we operate we ought to have them all handy so that we can use whatever is necessary for the case. We cannot tell from the outside what we are going to have on the inside. I disagree very materially with Dr. Cubbins' statement that the Lane plate does not cause any more traumatism or irritation than bone or ivory. In the first place, I do not think that it is proper from a purely mechanical standpoint. In the second place, those of you who have taken out Lane plates know that many of them have a collection of serum about them. I disagree with $\mathrm{Dr}$. Kreuscher that the infection is primary. Many of them show a little swelling and a seepage of fluid six weeks after. Dr. Cubbins took out a plate six years ago that $\mathrm{Mr}$. Lane put in eight years ago, because it was bothering the patient. It is true that all these things loosen up. You can say what you like about dead bone, ivory or autogenous graft, they all loosen up at some point in the procedure. After that they may tighten up if they are not warped, but I never saw a Lane plate tighten up after it was once loosened. If you were to be operated on, you would not care to have to undergo a second operation later to take out something that was put in to do the first job, when you could have had something put in to stay.

Dr. Frederick C. Kinder, Detroit: I must disagree with what Dr. Cubbins says about muscle interference in fractures with traction. I have operated and found muscle intervening no matter how hard I pulled. even on the Hawley table. I agree we should use every effort to get the fragments together without open operation. As to bone grafts, I do not think they are better than any other means of internal fixation. They do not give the rigidity in difficult cases that metal, ivory or beef bone often does. They are very useful, perhaps, in ununited fractures. The longer we wait in these muscle interposition cases, the slower will be the convalescence following the operation. Therefore, I am learning to try to recognize these cases and get my open operation done by the end of a week or ten days. The matter of Lane plates becoming septic is to my mind dependent on the surgeon only. I do not believe it is any wiser or more necessary to operate on bone with long instruments without the use of fingers than it is in the abdomen. I think the resistance of muscle and bone to infection is just as great as the resistance of the abdomen. I still believe that the use of gloved fingers does less harm and causes less traumatism than does a strictly instrumental technic.

Complete Hospital Data Lacking.-In no American city of ainy size is it possible to give the total number of cases admitted to the hospitals, both public and private, the diseases for which entrance was sought, the age and sex distribution of the patients, the duration of treatment and the result of the treatment. It is a blemish on the excellent work done by hospitals that this phase of their activities has been left undeveloped almost without exception in the United States.-H. Emerson, Hosp. Soc. Service 4:271 (Nov.) 1921.

\section{A COMPARATIVE STUDY OF ETHMOIDAL AND SPHENOIDAL OPERATIONS *}

\author{
J. J. SHEA, M.D. \\ MEMPHIS, TENN.
}

The appreciation that the posterior ethmoidal cells and the sphenoidal sinus are the causative factors in many of the optical nerve disorders has centered attention on this region. Formerly, the anterior ethmoidal cells held the center of the stage in our attention because of their relationship to the frontal sinus. The older operations were so designed that the anterior cells were first attacked and were more thoroughly exenterated at the expense of an uncertainty of thoroughness in the posterior region. If the sphenoidal sinus and the posterior ethmoidal cells are the important factors, then the successful operation must be based on thoroughness in their exenteration. In like manner, the curet, guided by the sense of touch, must give way to the trustworthy biting forceps, controlled by the sense of sight. The fundamental law of safe ethmoidal and sphenoidal surgery is to work by sight only, avoiding tearing by accomplishing each removal with a clean bite. It is intended to compare the intranasal operations and not to consider the radical operations.

\section{ANATOMY}

The ethmoidal and sphenoidal sinuses are so closely articulated as to be considered one structure. The division between the anterior and posterior cells cannot be made out surgically, nor can the posterior cells be completely exenterated without removing the pars ethmoiclalis, which will open the sphenoidal sinus. The middle and superior turbinates are only specialized portions of the ethmoidal bone. The optic nerve is in close relation with the lateral and superior aspect of the sphenoidal sinus and ustrally with the posteroexternal angle of the last posterior ethmoidal cell. Its course forward in the orbit carries it farther away from the inner orbital wall the farther it goes forward, so that it is increasingly removed from the possibility of contact with the anterior ethmoidal cells. Hence, in disturbances of the optic nerve, the usual or logical site of a causative nasal lesion is in the sphenoid or posterior ethmoidal cells. ${ }^{1}$

The middle turbinate is so situated that its posterior end is anterior to the sphenoidal sinus and is a reliable landmark in locating the sinus.

There is a type of spheno-ethmoidal labyrinth similar to the persistent infantile type of mastoid, that is, the cells are small and their walls firm, and this condition may be due to an arrested development. When this

* Read before the Section on Laryngology, Otology and Rhinology at the Seventy-Third Annual Session of the American Medical Ass sciation, St. Louis, May, 1922.

Wiener, Meyer: Ann. Otol,, Rhinol. \& 
type is encountered, the pathologic conclition present is chronic, and the postoperative healing is slow.

\section{PHYSIOLOGY}

The special sense of smell is a subject for consideration in ethmoidal surgery. The protection of the membrane lining the superior turbinate and the septum opposite to it will preserve this sense. It is very embar-

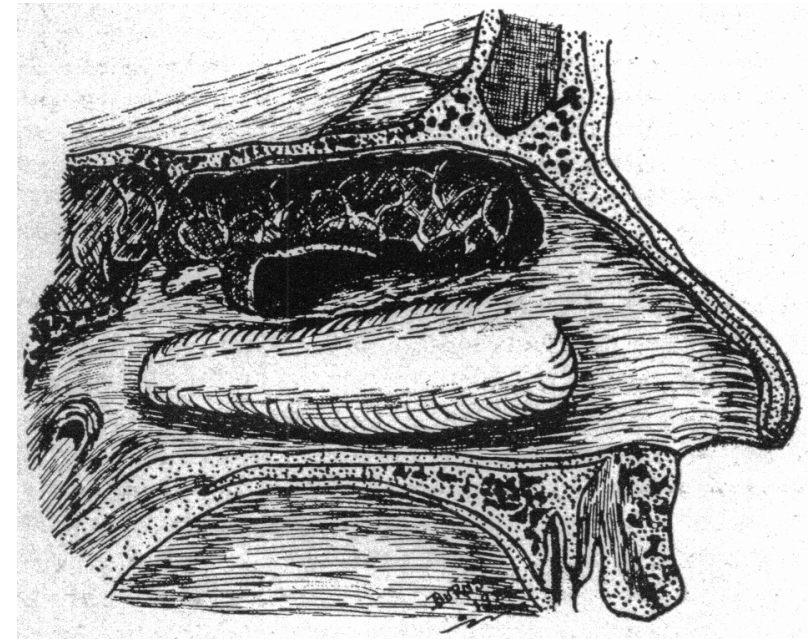

Fig. 2.-Completed operation: thoroughness of the exenteration of the post.rior ethmoidal cells.

rassing to the surgeon for the patient to lose this sense, but this will happen if the membrane lining the superior turbinate is totally destroyed.

\section{OPERATION}

A description will be first given of a composite operation that has for its advantage a greater chance of thoroughness in resecting the anterior wall of the sphenoid and exenterating the posterior ethmoidal cells; and then a comparison of its advantages with the usual textbook operation will be considered. The operation is based on the good points of operations discussed. Through the courtesy of Dr. Loeb I will use for illustration and description the operations as outlines in his book. ${ }^{2}$

The patient, having been thoroughly anesthetized (local preferred), is placed in a semiprone position or upright, with an assistant supporting the head. The position assumed by the patient should not be allowed to distort one's surgical anatomy. The middle turbinate is completely removed. This will always leave a fleshy tag at its postero-inferior attachment. The sphenoidal sinus is situated immediately posterior to this tag, and at all times this tag may be used as a landmark in orientating oneself in this region.

By passing the sphenoidal punch alongside this tag the sphenoidal sinus can be directly entered at its safest point (the inferomesial aspect). The pars nasalis is resected with due reverence to the position of the posterior branch of the nasopalatine artery. Yankauer has given us a method of attacking this vessel and eliminating it as a complicating factor. This is detailed under his operation. The resection is carried outward and, by the removal of the pars ethmoidalis, the posterior ethmoidal cells are entered. If there are any atypical ethmoidal cells surrounding the sphenoid or any extending laterally, they are easily entered and their partitions removed. A small piece of gauze i.j

2. Loeb, II. W.: Operative Surgery of the Nose, Throat and Ear, St. Louis, C. V. Mosby \& Co. now placed so as to fit against the nasopharynx and lessen the amount of blood that will run down into the throat. The exenteration of the ethmoidal cells is accomplished with suitable biting forceps, starting from behind and working forward at the level of the attachment of the middle turbinate. The cells are thus reduced in layers from above downward. The cells which lie above the attachment of the middle turbinate are removed by using the forceps in such a position that the longer blade is toward the median line. This will prevent injury to the cribriform plate. The mucous membrane covering the uncinate is reduced, and with suitable forceps the anterior cells are removed. Occasionally it will be necessary to use a curet in this anterior position to expose the foremost cells, but their removal is accomplished with biting forceps. If there has occurred a hypertrophy of the ethmoidal cells, to such a degree that they obstruct the vision of the posterior region, then the obstruction must be reduced before the more delicate posterior surgery is undertaken. In like manner, if the septum is deflected and will interfere with free instrumentation at the time of operation or in the after-treatment, it should be resected.

As all the operating is done by sight, the field must be kept clean of blood. The use of a suction tube will expedite matters. At first we used a glass drinking tube by attaching it to the suction side of the ether suction machine, but it was found to be too large to enter many of the sphenoidal cavities, so $\mathrm{Mr}$. V. Mueller made us a removable tip for the instrument described by Walker.

Yankauer ${ }^{3}$ recommends irrigation of the nares with iced saline solution when the action of the epinephrin has died away.

\section{PRATT'S OPERATION}

Dr. J. A. Pratt ${ }^{4}$ presented in 1919 an operation in which the middle turbinate was allowed to remain. His description of the technic is given below.

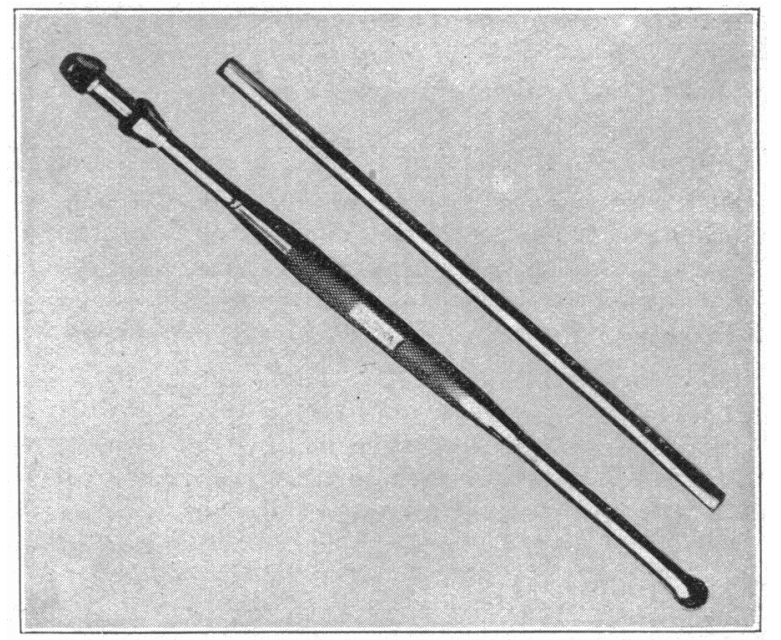

Fig. 3.-Suction instrument for intranasal use, made by moclifying th: tip of the instrument designed by Walker.

The anterior cells are opened with the nasal cutting forceps, biting just under the anterior end of the middle turbinate, pointing toward the corner of the eye and continuing backward and upward as long as there is soft bone encountered. - . We take the straight end of the curet and, with a

3. Yankauter, Sidney: The Complete Sphenc-Ethmoid Operation, Laryngoscore $\mathbf{3 1}: 831$ (Nov.) 1921.

4. Pratt, J. A.: Tr. Am. Acad. Ophth. \& Oto-Iaryngol., 1910. 
firm but gentle stroke in every direction, curet out all of the partitions of the soft cells. . . With the angle end of the curet any anterior cells are now removed, enlarging the space upward toward the frontal sinus. We now cut out the floor of the capsule back to the sphenoid sinus, giving a free open space under the entire length of the middle turbinate. . . If, after a suitable length of time, the discharge does not cease, the nose can be recocainized and the operation easily extended into the sphenoid, or by the use of a

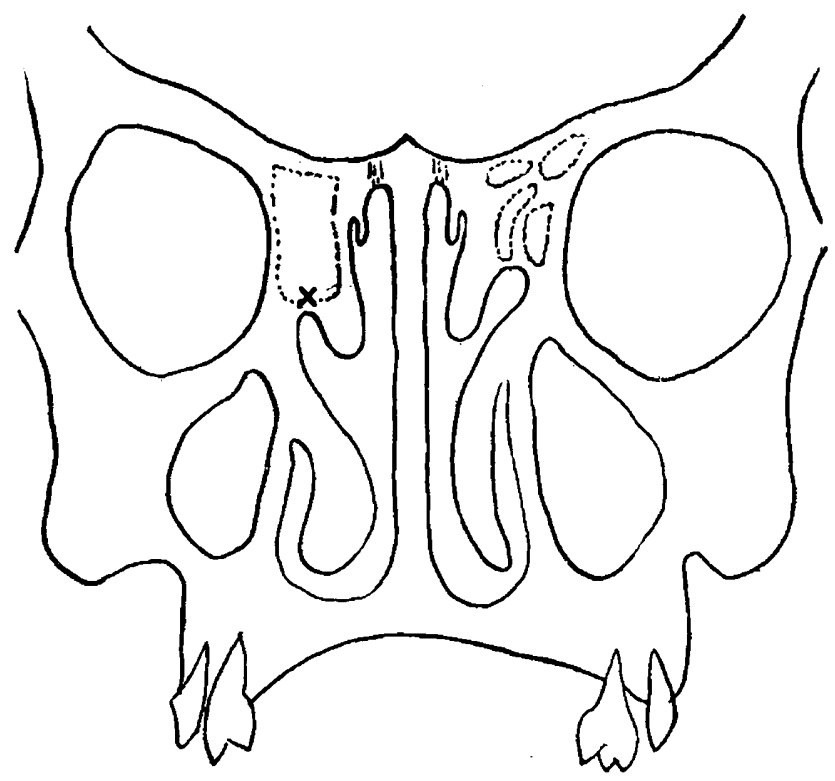

Fir +-Pratt's operation: protection provided by the midclle tu binate for the cribriform plate during the exenteration.

Thompson-Good rasp, a large opening can be made into the frontal sinus.

Pratt also states that he has not yet found it necessary to remove any part of the middle turbinate in order to exenterate the ethmoids or open the frontal or sphenoidal sinuses, intranasally.

Commont.-The sphenoidal sinus and the posterior ethmoidal cells are possible of being opened in this manner, but it is very difficult to keep them open. The débris will pile up as one works back and detract from one's security while exenterating the posterior cells, especially if there are any atypical cells, such as often encircle the sphenoidal sinus. The capsule of the persistent infantile type of the spheno-ethmoidal labyrinth is often firmer, and the posterior cells are smaller than normally, and the presence of the middle turbinate will interfere with the precision necessary for accurate exenteration of the posterior cells. Any sphenoid that requires a resection of its anterior wall should be accessible to postoperative treatment, and even the remains of the fleshy posterior attachment of the middle turbinate will block the drainage of the sinus.

\section{MOSHER'S OPERATION}

Mosher removes that portion of the middle turbinate which lies below the summit of the superior meatus with scissors and enters the ethmoidal labyrinth at the upper overhang with a sharp curet. The curettement is continued through the opening thus made and the curet is carried first forward against the ascending process of the superior maxilla and then downward and backward between the orbital plate and the middle turbinate as far as the ethmoid cells extend : ${ }^{2}$

The middle and lower half of the superior turbinate bones are then carefully removed by cutting straight backward as high above the middle turbinate as the scissors punch can be made to engage. One blade is placed in the exenterated labyrinth and the other follows backward in the olfactory slit. When the scissors punch has cut its way to the front wall of the sphenoidal sinus, the middle turbinate and the lower part of the superior turbinate are removed with a snare or twisted out with a small pair of Luc forceps. The sphenoidal sinus is punctured with the curet as close to the septum as possible if the ostium cannot be located. A probe bent at a right angle is introduced into the sinus and turned outward and brought forward against the external part of the front face of the sinus, and its width ascertained. This will show how much of the anterior wall can be removed. With a small right angle punch the anterior sphenoidal wall is resected. Avoid curetting the outer superior angle of the posterior cell. As a finishing touch, the curet is carried outward to os planum posteriorly and brought forward along its inner surface."

Comment.-This operation did more for the future of ethmoidal surgery than any other operation. It meets the needs of anterior work, but has the same disadvantages as the Pratt operation, of being a curet operation, and that the operative approach is from before backward. Some of our best results were obtained with this method, but the number of failures to obtain and retain a dry naris was too great. These failures were due to the missing of some of the cells by the piling up of the débris and the tearing of the curet. When the frontal sinus is to be drained through the ethmoids, the knowledge of the distribution of the anterior cells about the frontal duct is imperative, and to Dr. Mosher belongs the credit of orientating $11 \mathrm{~s}$ in this region.

\section{BALLENGER'S OPERATION}

Ballenger's operation is selected to represent the group of operations devised with the idea of removing the ethmoidal labyrinth en masse. With a specialiy

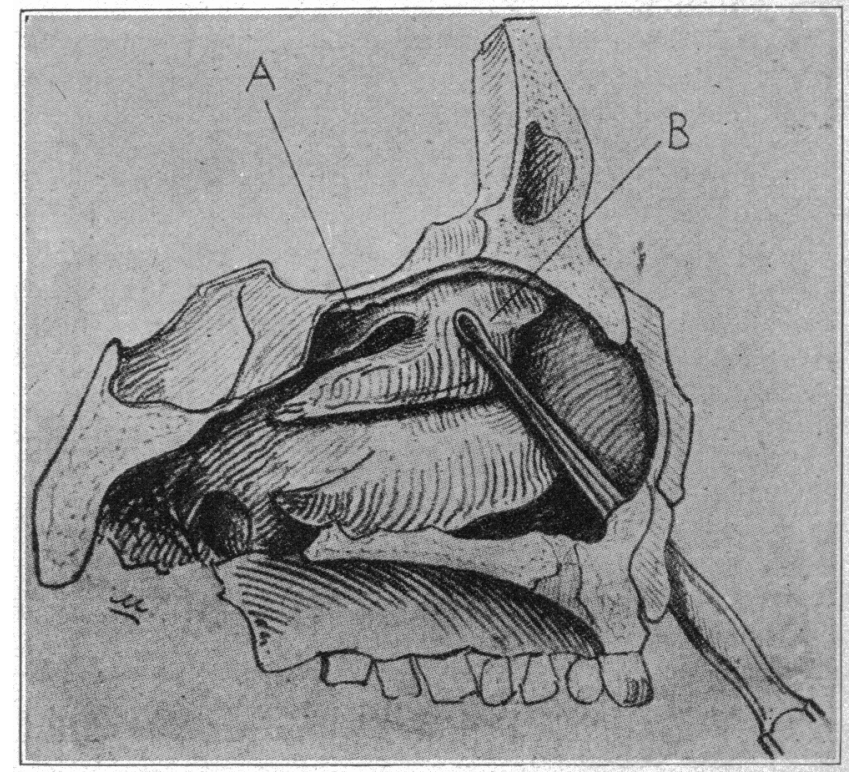

Fig. 5.-Mosher's operation: point of entrance into the ethmoidal labyrinth.

designed knife the ethmoidal labyrinth was carved fres around its posterior, superior and anterior borders, and the resected mass withdrawn from the nose.

Comment.-The spheno-ethmoidal labyrinth is too delicate, and its relationship with the meninges is too

\footnotetext{
5. Mosher, H. P.: Laryngoscope, September, 1913.
} 
close, to sanction such radical procedures en masse. Then, too, there are so few perfect labyrinths, and the anatomic variations are so great, that the method is limited to only selected cases, in the hands of a very few surgeons.

\section{HAJEK'S OPERATION}

Hajek resected the middle and superior turbinate with his hook and reduced the anterior wall of the

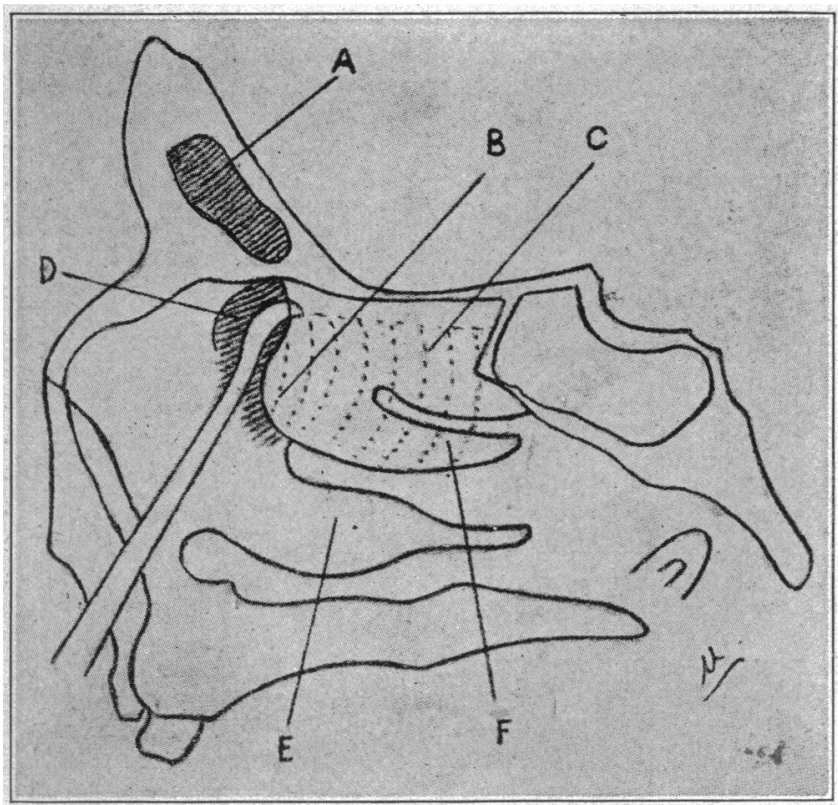

Fig. 6.-Mosher's operation: exenteration of the ethmoidal cells from before backward.

sphenoid and the posterior ethmoidal cells with the same hook, by inserting the hook posteriorly and drawing it forward and removing the shreds with forceps. ${ }^{1}$

Comment.-This was the first operation which attacked the sphenoid primarily, and which worked from behind forward.

\section{SLUDER'S OPERATION}

Sluder's technic is an improvement on that of Hajek's, and the hook is replaced by a Sluder ethmoid knife, so constructed that the cutting edge is turned at right angles to the shaft and sharpened so as to cut on the pull, with the lower part of the shaft supporting a sharpened edge. The middle and superior turbinates are removed with the knife. The sphenoid is attacked directly, and the pars nasalis and the pars ethmoidalis are resected, thus exposing the posterior ethmoidal cells. The ethmoidal capsule is resected by a series of strokes from behind forward, and working away from the roof. With suitable forceps, the fragments are removed and the field is made surgically clean. $^{2}$

Comment.-The same may be said of this method as of the method of Hajek, that the sphenoid and the posterior ethmoidal cells may be thoroughly exenterated. Early attention to the posterior region insures the success of the operation.

\section{REAVES' OPERATION}

Reaves, ${ }^{6}$ in 1919 , emphasized the value of sharp biting forceps, and the fact that the only acceptable operation is one that completely exenterates all the cells

6. Reaves, Perry: Ethmoidal Operation for Pansinusitis, Tr. Acad. Ophth. \& Oto-Laryngol., 1919. and resects the anterior wall of the sphenoid. He also calls attention to the fact that the mucoperiosteum curetted or stripped by dull forceps from the roof and wall will be covered over by granulation tissue, which becomes scar tissue or a boggy mass to harbor infection. Reaves removes "the middle turbinate, the vertical plate of the ethmoid with the superior turbinate and lower half or two thirds of the ethmoid cell with his ethmoid knife," the roof is orientated, and "then follows the removal of the ethmoidal cells forward and backward or vice versa with forceps adapted in size to engage the cells which are even higher than the nasal roof."

Commont.-Reaves has given us not only a method but also the necessary instruments to accomplish our purpose. He also brought out thoroughly the fact that the lining mucoperiosteal membrane should be protected and sufficient time taken to completely exenterate all cells possible of reaching by sight.

\section{YANKAUER'S OPERATION}

Yankauer, in 1920, gave an encouraging outlook to the modern spheno-ethmoidal operation, and added several very valuable points to its technic. The isolation of the posterior branch of the nasopalatine artery as it crosses the face of the sphenoid and by crushing, eliminating it as a complicating factor, is worthy of notice. The use of iced physiologic sodium chlorid solution as a douche during the operation to check the oozing after the epinephrin has ceased to act, and

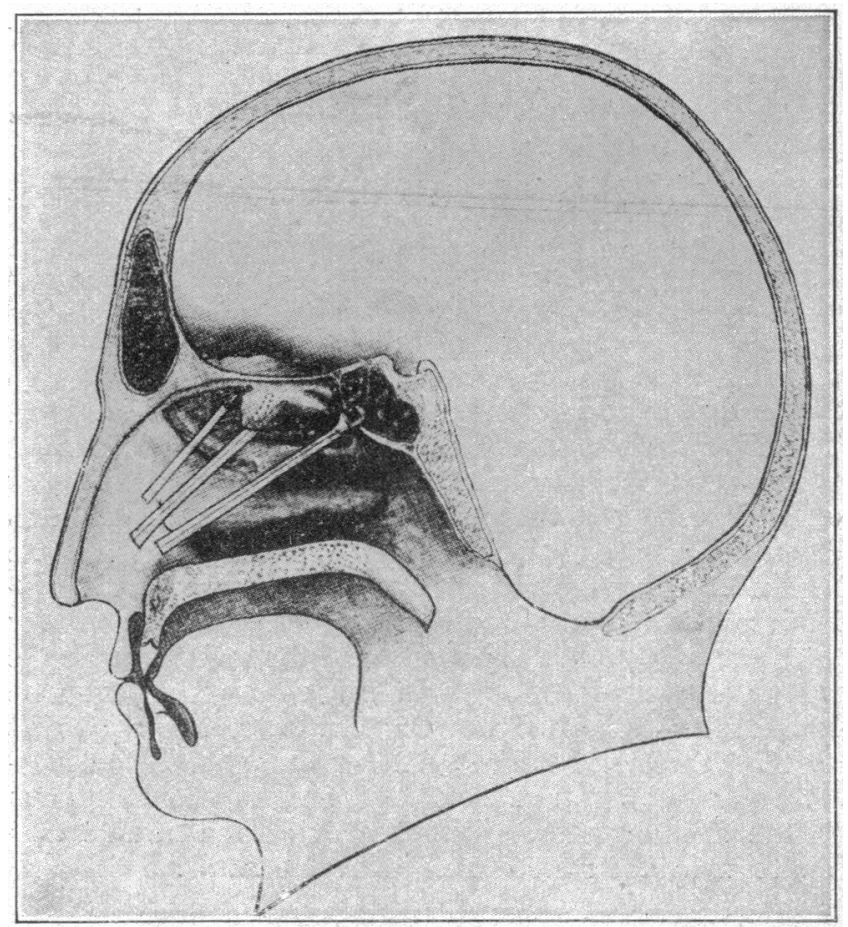

Fig. 7.-Reaves' operation: use of the 15 degree angle ethmoidal forces in removing the middle turbinate; position of the sphenoidal punch while resecting the anterior wall of the sphenoid.

the use of bone wax to plug the anterior ethmoidal artery when it is a source of hemorrhage, are worthy of praise. Yankatuer ${ }^{3}$ thus describes a very sensible and thorough operation: The middle turbinate is removed with a Holmes scissors and snare. "The most prominent cell is attacked with forceps. From this point the opening of the cells proceeds in a backward direction until all of the cells of the posterior group 
and the sphenoid cell have been opened, their entire inner walls and the partitions which separate them being completely removed and all converted into one single cavity." The sphenoid is attacked early in the operation and its anterior wall resected, exposing any hidden posterior cell. Yankauer localizes his roof by utilizing the upper limits of the sphenoid or the posterior ethmoidal cell. "The anterior cells are opened from behind forward, until the anterior limiting line has been reached, which is the rounded border of the nasal process of the superior maxilla."

Comment.-This operation is full of wisdom and, if followed, will render favorable results and be a source of benefit to the chronic ethmoidal cases.

\section{ABSTRACT OF DISCUSSION}

Dr. Frank L. Dennis, Colorado Springs, Colo.: Dr. Shea has emphasized that it is much better to work from behind forward, because one has the advantage of seeing what one is doing. The method of proceeding from before backward has the disadvantage of obscuring the field, not only by blood, but the entire front of the nose is filled with a mass of débris. Another point he brought out that is of importance is that it is necessary first to create a passageway for the operation. In other words, if the septum is deflected to one side, if the anterior end of the turbinate is enlarged, one must first create room for operating. The impression is given that the ethmoid operation does not amount to much. That is not true. There is too close a relation of too many important structures for any one to operate in the ethmoid region without the greatest care and without being able to see what he is doing. Not only should a roentgenogram be made of the sphenoid and ethmoid, but the nose itself should be studied beforehand. Dr. Shea did not say anything about hemostasis or anesthesia. Both are very important in the success of the operation. Another point is the importance of the after-care of these patients. The general idea is to leave in place as much as possible of the lining membrane; but whether that is practicable in many cases is a question in my mind. Many times one must take out much more membrane than one thinks desirable. Therefore, I think that in all these ethmoid operations the importance of the after-care should not be overlooked.

Dr. T. E. CARmody, Denver: The one point we must keep in mind is that we are coming to recognize the value of controlling hemorrhage. The nasal operations that we saw up to two or three years ago were bloody operations. The control of hemorrhage as brought out by Yankauer and Shea is simple and will help a great deal. I have found that an ordinary large sized eustachian catheter will answer the same purpose as the suction apparatus or Shea's instrument. In some cases the middle turbinate can be left, but we ought to be careful about leaving it when there is marked enlargement in the middle turbinate, because it will close the space and we shall be unable to take care of after-treatment as well.

Dr. John A. Cavanaugh, Chicago: It is a difficult proposition to make roentgenograms that show positively whether the sphenoid is a definite size unless one injects it. I have injected these sphenoids with barium solution suspended in malted milk. I was surprised at the variations these sinuses revealed. The ethmoids on one side are always superimposed on the ethmoids of the opposite side, and it is difficult to separate them in the picture. In the last year I have been cocainizing the nose and introducing small films into the nasal cavity between the middle turbinate and the septum, placing markings on the anterior wall of the sphenoid and various points of the ethmoids and along the lower edge of the middle turbinate. This work is not completed. I hope that something will come of it. Regarding the sphenoid operation, and the picture showing the removal of the anterior wall of the sphenoid, some of you may have seen the batr. I devised for removing this wall. I have not been able to find biting forceps to take down this wall of the sphenoid cormpletely. But with my burr one can remove the entire wall and floor, which gives perfect drainage.

DR. EDWIn McGinnis, Chicago: when Dr. Mosher first brought out the anatomy of the ethmoid region with complete exenteration, curettage and cleaning up afterward with biting forceps, it seemed that we had reached very satisfactory results in operative surgery. A year later Dr. Shambaugh gave some data of exenteration which seemed to emphasize the result. During the last year, however, I have had three or four patients who had had complete exenteration of the ethmoid and who had reinfection of the cells that remained. If we could exenterate the sphenoid and antrum, I think that exenteration of all the cells would be the ideal operation. Of course, it is impossible to eradicate the antrum-Killian used to obliterate the frontal, but it is impossible to eradicate the sphenoid. One gets very enthusiastic about this thing, because if one can clear up the olfactory region in the narrow space between the middle turbinate and the turbinal plate, very often these patients will recover. A high septum operation will clear it up in many cases. Many of the patients do not do well. Study of the ethmoid region will reveal that the middle turbinate divides the two groups of cells, anterior and posterior, and the posterior cells are larger and have larger openings. But it is hard to examine these posterior cells; the anterior group are easy to observe. I proposed a drainage operation two or three years ago. I made an incision into the anterior ethmoid cells up to the frontal sinus, extending this through the posterior cells and back to the anterior wall of the sphenoid. Dr. Yerger gave the statistics in regard to infection of the sphenoid at the county hospital in the cases that came to postmortem. The sphenoidal sinus was the least infected of all of the nasal accessory sinuses. If one drainage operation does not do any good, one can do another; and, if the second drainage operation does not give results, one can then exenterate. For two years I have not disturbed the middle turbinate and have not exenterated the ethmoid labyrinth, and the patients do just as well as those who have had exenteration of the ethmoid.

Dr. Fred J. PratT, Minneapolis: I want to protest against removing the middle turbinate. The middle turbinate is a good thing to have as a guide during an ethmoid operation. The openings in the cribriform plate are between the middle turbinate and the septum, and if one removes the turbinate one opens an avenue for infection into the brain which can be avoided if one keeps the middle turbinate and works under it: Speaking of cleaning out the ethmoid, every one knows that there are accessory cells. Often we cannot find these the first time. The only thing to do, after exenterating the ethmoid, if the case does not clear up, is to go back and find out where the trouble is. The doctor spoke about not being able to keep the space open under the turbinate if it is left in place. Granulations form even if one removes the turbinate; and, if the turbinate is left, all that is necessary to do is to follow around the opening and bite off the granulations. One can do this just as well by leaving the turbinate as by removing it. Another thing tending to prove that the middle turbinate is of some use is that one will find in cases in which the turbinate was removed years before that Nature has put soft hypertrophies on the lateral wall and septum, trying to narrow the space. I think that this is proof that the middle turbinate is of some use.

Dr. John J. Shea, Memphis, Tenn.: It requires from six to twelve months to obtain permanent results after an exenteration of the ethmoids in many of the cases, and during this period the patients should be treated carefully. Unless the sight is at stake, an ethmoidal case should be treated a month or two before operating, unless gross pathologic conditions are present. The discharge will change its character after the cells have been exenterated, but will not cease entirely. If the discharge remains purulent, scabs will be formed; but the cases are not troubled by dryness, as one would expect. A method of outlining the sphenoid of one side, when inspection fails to be satisfactory, is to insert the Holmes nasopharyngoscope into the other sphenoidal cavity 
and transilluminate the questionable cavity. The paper did not deal with the indications for the operations. Dr. Carmody spoke of the eustachian catheter as a suction instrument. The one I improved is the outgrowth of using first a catheter and then glass drinking tubes. The latter are the more serviceable.

\section{A CONSIDERATION OF ACUTE AURAL DISEASE IN CHILDREN *}

\section{A. SPENCER KAUFMAN, M.D. PHILADELPHIA}

Acute infections of the middle ear are met with at all times, but from December to April of each year they are exceedingly numerous, and as surely as they appear in succeeding years they vary in symptomatology and severity. In the past season, for instance, the number of cases of acute otitis media was greater than usual, and the severity of the symptoms was out of proportion to the morbidity of the disease.

It is indeed surprising how seldom aural examinations are practiced routinely; and it is well to emphasize at the beginning that, when such an examination is made and reveals trouble, and the proper methods of treatment are instituted, we have not only treated the existing condition, but have also applied prophylaxis against permanent loss of function and the dangerous intracranial complications.

\section{ETIOLOGY}

Considering the causative factors, we find the most common source of acute middle ear inflammation in local infection of the nose and throat, as well as in the general infections in which nose and throat involvement is more or less constant. We have but to remember that the mucous membrane lining the nose and throat continues up the eustachian tube; lines the middle ear cavity, attic and mastoid antrum, and forms the internal layer of the tympanic membrane, to realize with what ease infections involving the nasopharynx may, in turn, infect the ear. Influenza, measles and pneumonia are the most important general infections; but all of the other exanthemas and acute infectious diseases play important parts. In this class of cases, a routine inspection of the ears should be made, as one would examine the chest and abdomen for evidence of new developments. Local causes are the infections confined to the upper respiratory tract, such as acute rhinitis and obstructive conditions. Anything that interferes with the proper ventilation of the nasopharynx and eustachian tubes is a direct or indirect causative factor. Adenoids, by their direct blockage, and hypertrophied tonsils, by the upward pressure exerted on the tubes, are, of course, the most common factors. The removal of diseased tonsils and adenoids is the best prophylactic measure at our command in the prevention of aural involvement. This is true not only in the acute form, but also in the chronic suppurative and nonsuppurative.

It must be borne in mind, however, that, while the susceptibility to infectious processes is materially reduced by this operation, the possibility of their occurrence still exists when we have an acute nasopharyngitis, either primary or secondary. The vicious habit of teaching children to blow their noses by holding one or both nostrils tightly closed and applying

* Read before the Section on Diseases of Children at the Seventy Third Annual Session of the American Medical Association; St. Louis, May, 1922. expulsive force should be discouraged as dangerous to the ear. Chronic general diseases, such as tuberculosis, syphilis, scurvy, diabetes and nephritis, are often underlying conditions; but, except in the case of tuberculosis, in which we recognize a distinct type of otitis, middle ear involvement is probably due to lowered resistance, rather than to a distinct local manifestation. We all must agree that purulent otitis media occurs too frequently during dentition in infants to be a mere coincidence. The probable explanation is that, at the time of teething, there is general congestion of the entire mucous membrane of the nose and nasopharynx, causing a blockage of the tubes.

\section{PATHOLOGY}

The pathology in a direct infection does not vary from that of a condition involving the mucous membrane of any other structure; but there is a distinct difference in that class of cases that might be called secondary infection. By that, I mean those in which the eustachian tube is sealed off and the air in the tympanic cavity becomes absorbed. With its gradual disappearance, there is an outpouring of mucus, and we then have a condition termed hydrops exvacuo. If this fluid remains sterile, it will be gradually absorbed as the inflammation subsides and ventilation of the tympanic cavity is again established. This will clear up with proper treatment applied to the nose and nasopharynx; but, if it is of longer duration, active surgical treatment, such as will be spoken of later, must be applied.

SYMPTOMS AND TREATMENT

It is well to consider the symptomatology and treatment of the catarrhal and purulent otitis together, because, although we have a distinct disease in the acute catarrhal otitis media, every case of the suppurative variety must pass through the catarrhal first. No matter how brief this stage may be, it exists nevertheless and the symptoms that present themselves in the suppurative type are, with few additions, exaggerations of those that we find in the catarrhal.

First and foremost is the development of pain, which is usually worse at night. This varies from a slight discomfort to an exceedingly excruciating earache. The ordinary "earache of childhood" is attended by pain which is very severe but of short duration; and little can be seen on examination except, possibly, some redness along the handle of the malleus or of Shrapnell's membrane. Tenderness can also be elicited by pressure in front of the tragus and immediately below the lobe. An important thing to remember is that, in the acute infectious diseases, there may be an absence of pain; and we often see, during the convalescence, that the temperature goes up for some unknown reason. If the ear has not been examined, it is not an infrequent occurrence to have a discharge from the external auditory canal as the first evidence of middle ear involvement. Symptoms of impaired function, such as tinnitus, are rarely complained of, even by older children, although the parents may notice a loss of hearing. Fever is always present in the suppurative variety, but is usually absent in the catarrhal, when the etiologic factor is afebrile. Two significant symptoms of acute ear disease in infants are the attempt to get the hand up to the side of the head affected, and rolling of the head from side to side. The latter symptom has been spoken of so much that an occasional diagnosis of ear disease is made without careful examination, and later it is found that this action is due to other causes. 